\title{
Ciprofloxacin treatment of bacterial endocarditis involving prosthetic material after cardiac surgery
}

\author{
N M Brown, R J Körner, C E Zollman, R P Martin, M R Millar
}

\begin{abstract}
Two children with cyanotic congenital heart disease and Gram negative bacterial infection of prosthetic material after cardiac surgery were treated successfully with oral ciprofloxacin, initially in combination with netilmicin. The use of oral ciprofloxacin allowed prolonged outpatient treatment to be given, avoiding the need for intravenous access and early repeat surgery.

(Arch Dis Child 1997;76:68-69)
\end{abstract}

Keywords: endocarditis; prosthetic material; ciprofloxacin.

Infective endocarditis in children is rare, but carries a significant morbidity and mortality. Postoperative infection where prosthetic material has been implanted into the vascular system is uncommon, ${ }^{1}$ but is very difficult to eradicate. It may be fatal despite surgical removal of the infected material. ${ }^{2}$ In a recent review of the use of Blalock-Taussig shunts in 92 children the overall mortality was found to be $9.8 \% .^{1}$ There was evidence of sepsis in three of the nine deaths $(33 \%)$. We report the successful treatment of Gram negative bacterial infection associated with prosthetic material in two boys with severe underlying cardiac abnormalities using a combination of ciprofloxacin and netilmicin.

\section{Patients and methods}

CASE 1

A 4 year old boy presented with complex cyanotic heart disease comprising normal situs, an absent right atrioventricular connection, a univentricular atrioventricular connection between the left atrium and the right ventricle, and a double outlet of the right ventricle with severe pulmonary stenosis. He had had a balloon septostomy performed at the age of 1 year, with insertion of a modified right Blalock-Taussig shunt. Three years later this had become almost completely occluded, requiring the insertion of a left Blalock-Taussig shunt. His postoperative course was complicated by chylothorax and persistent fever. Enterobacter cloacae was isolated from both bottles of two sets of blood cultures taken seven days apart. He did not respond to cefotaxime, and this was replaced by ceftazidime and netilmicin. He was discharged home well, but during the next four months he experienced intermittent febrile episodes, was found to have a raised $\mathrm{C}$ reactive protein, and was readmitted to hospital. $E$ cloacae was isolated from a further set of blood cultures. There were no new clinical or echocardiography findings, but in the absence of any other infective focus and since vegetations on prosthetic material may not be visualised, we considered infection of the Blalock-Taussig shunt likely. $\mathrm{He}$ was treated with oral ciprofloxacin $15 \mathrm{mg} / \mathrm{kg} /$ day in two divided doses and intravenous netilmicin. His temperature settled after three days and his $C$ reactive protein returned to normal. In vitro synergy was demonstrated between ciprofloxacin and netilmicin (ciprofloxacin: minimum inhibitory concentration (MIC) 0.03 $\mathrm{mg} / \mathrm{l}$, minimum bactericidal concentration (MBC) $0.06 \mathrm{mg} / \mathrm{l}$; netilmicin: MIC $1.0 \mathrm{mg} / \mathrm{l}$, MBC $1.0 \mathrm{mg} / \mathrm{l}$; ciprofloxacin plus $0.5 \mathrm{mg} / \mathrm{l}$ netilmicin: MIC $0.015 \mathrm{mg} / \mathrm{l}$, MBC 0.015 $\mathrm{mg} / \mathrm{l})$. Serum ciprofloxacin concentrations on $15 \mathrm{mg} / \mathrm{kg} / \mathrm{day}$ were $0.2 \mathrm{mg} / 1$ (before the dose) and $0.7 \mathrm{mg} / 1$ (one hour after the dose). Increasing the ciprofloxacin dose to 22.5 $\mathrm{mg} / \mathrm{kg}$ /day resulted in serum concentrations of $0.2 \mathrm{mg} / \mathrm{l}$ (before the dose) and $1.3 \mathrm{mg} / \mathrm{l}$ (one hour after the dose). He was treated for five weeks, with ciprofloxacin alone for the final two weeks. There were no recognised antibiotic side effects. He has remained infection free during three years' follow up, and has recently undergone further surgical repair by total cavopulmonary connection.

\section{CASE 2}

An 11 year old boy was admitted with a two week history of fever, rigors, increasing breathlessness, lethargy, anorexia, and ankle swelling. He was febrile $\left(40^{\circ} \mathrm{C}\right)$, but there were no localising signs of infection, and there had been no obvious precipitating event. He had been born with pulmonary atresia and a large ventricular septal defect (VSD), and had a Blalock-Taussig shunt inserted at the age of 18 months. Corrective surgery had been performed at the age of 6 years, with the insertion of a right ventricle to pulmonary artery valved conduit and a prosthetic patch to close the VSD. Two years later, stenosis at the lower end of the conduit required a further operation. He remained well until this admission three years later. $\mathrm{He}$ was treated initially with flucloxacillin and cefotaxime. Haemophilus aphrophilus was isolated from five sets of blood cultures. The isolate was sensitive to ampicillin, cefotaxime, netilmicin, and ciprofloxacin by a disc diffusion method. Echocardiography showed no evidence of vegetations, but infective endocarditis was considered the most likely diagnosis in view of the prosthetic material in his heart and the absence of any other site of infection. Therapy was 
changed to oral ciprofloxacin $15 \mathrm{mg} / \mathrm{kg} /$ day in two divided doses and intravenous netilmicin 4 $\mathrm{mg} / \mathrm{kg}$ once daily, and after one week, to ciprofloxacin alone. Assay of ciprofloxacin after one week showed satisfactory serum concentrations (before the dose $0.8 \mathrm{mg} / \mathrm{l}$, one hour after the dose $2.6 \mathrm{mg} / \mathrm{l}$ ). Symptoms resolved quickly, although his fever settled more slowly over two weeks. This may have been related to a vasculitic rash and immune complex mediated glomerulonephritis which complicated his recovery. We did not consider it was related to ciprofloxacin or any other concurrent medication. He had no joint symptoms. He remains well three years after discharge having completed a six week course of ciprofloxacin.

\section{Discussion}

The use of ciprofloxacin and other 4-fluoroquinolone antibiotics in children has been limited by the observation of cartilage toxicity in weight bearing joints in experiments with young animals. ${ }^{34}$ However, experience of their use in clinical conditions where they are considered to be the treatment of choice, for example, children with cystic fibrosis or infection with Salmonella typhi, has not shown such toxicity in humans. ${ }^{45}$

In our two patients, we considered ciprofloxacin to be the optimal treatment for several reasons. First, both children had complex cardiac abnormalities requiring repeated surgical intervention. Prosthetic material had been implanted. Although repeat surgery is commonly required in such infections we considered it important that this should be avoided if at all possible. Eradication of infection when prosthetic material is present can be difficult, even when optimal antibiotic therapy is used, ${ }^{6}$ probably because of formation of a protective biofilm consisting of an anionic matrix of exopolymers excreted by sessile bacteria colonising surfaces. Ciprofloxacin has properties which enable it to penetrate and kill bacteria even under these conditions. ${ }^{7}$

Secondly, a $\beta$-lactam/aminoglycoside combination had failed to eradicate infection in one of the children. We found the combination of ciprofloxacin and netilmicin synergistic against $E$ cloacae. Synergy between ciprofloxacin and aminoglycosides against Gram negative organ- isms has been reported previously, ${ }^{8}$ but other studies have shown only an additive effect, and not antagonism. ${ }^{9}$ In critical infections such as endocarditis this may be important.

Finally, the pharmacokinetic properties of ciprofloxacin allow prolonged oral treatment to be given, avoiding the need for inpatient treatment and the potential further problems associated with intravenous lines. However, when treating children with ciprofloxacin the paucity of pharmacokinetic data needs to be considered. Peltola et al found that the elimination half life was shorter and that the area under a serum concentration versus time curve was smaller in children than in infants and adults. ${ }^{10}$ This suggests that, in serious infections such as infective endocarditis, dosage regimens may need modification.

In summary, endocarditis should be considered in patients with bacteraemia when prosthetic material has been implanted. The absence of vegetations on echocardiography does not exclude endocarditis. Fluoroquinolone antibiotics have properties that may eradicate susceptible organisms from prosthetic material. Oral treatment with a fluoroquinolone antibiotic allows outpatient treatment and avoids problems associated with intravascular lines.

1 Gold JP, Violaris K, Engle MA, et al. A five year clinical experience with 112 Blalock-Taussig shunts. F Card Surg 1993;8:9-17.

2 Carvalho JS, Belcher P, Knight WB. Infection of modified Blalock shunts. Br Heart 7 1987;58:287-90.

3 Schaad UB. Use of quinolones in pediatrics. Eur $\mathcal{F}$ Clin Microbiol Infect Dis 1991;10:355-60.

4 Schaad UB, Wedgwood J. Lack of quinolone-induced arthropathy in children. $\mathcal{F}$ Antimicrob Chemother 1992;30: 414-6.

5 Kubin R. Safety and efficacy of ciprofloxacin in paediatric patients-review. Infection 1993;21:413-21.

6 Hoyle BD, Alcantara J, Costerton JW. Pseudomonas aeruginosa biofilm as a perfusion barrier. Antimicrob Agents Chemother 1992;36:2054-6.

7 Eng RHK, Padberg FT, Smith SM, Tan EN, Cherubin CE. Bactericidal effects of antibiotics on slowly growing and non-growing bacteria. Antimicrob Agents Chemother 1991; 35:1824-8.

8 Chalkley LJ, Koornhof HJ. Antimicrobial activity of ciprofloxacin against Pseudomonas aeruginosa, Esthe killing curve method: antibiotic comparisons and synergistic interactions. Antimicrob Agents Chemother 1985; 28:331-42.

9 Neu HC. Synergy and antagonism of combinations with quinolones. Eur $\mathcal{F}$ Clin Microbiol Infect Dis 1991;10:255-61.

10 Peltola H, Väärälä M, Renkonen O-V, Neuvonen PJ. Pharmacokinetics of single-dose oral ciprofloxacin in infants and small children. Antimicrob Agents Chemother 1992;36:1086-90. 